\title{
Recent Manufacturing Advances for Spiral Bevel Gears
}

Robert F. Handschuh and Robert C. Bill

Propulsion Directorate

U.S. Army Aviation Systems Command

Lewis Research Center

Cleveland, Ohio

Prepared for the

Aerotech '91

sponsored by the Society of Automotive Engineers

Long Beach, California, September 23-26, 1991 


\title{
RECENT MANUFACTURING ADVANCES FOR SPIRAL BEVEL GEARS
}

\author{
Robert F. Handschuh and Robert C. Bill \\ Propulsion Directorate \\ U.S. Army Aviation Systems Command \\ Lewis Research Center \\ Cleveland, Ohio 44135
}

\section{SUMMARY}

The U.S. Army Aviation Systems Command (AVSCOM), through the Propulsion Directorate at NASA Lewis Research Center, has recently sponsored projects to advance the manufacturing process for spiral bevel gears. This type of gear is a critical component in rotary-wing propulsion systems. Two successfully completed contracted projects are described. The first project addresses the automated inspection of spiral bevel gears through the use of coordinate measuring machines. The second project entails the computernumerical-control (CNC) conversion of a spiral bevel gear grinding machine that is used for all aerospace spiral bevel gears. The results of these projects are described with regard to the savings effected in manufacturing time.

\section{INTRODUCTION}

Spiral bevel gears are used when power must be transferred between intersecting shafts. The actual shaft angle can be any reasonable amount, thus allowing greater design flexibility. In aerospace applications, such as helicopters, spiral bevel gears are presently utilized in all main and tail rotor transmissions. These gears are a critical power path component whose failure could result in a lost aircraft. Thus, the manufactured hardware must be the highest possible quality.

The manufacture of aerospace spiral bevel gears is very difficult. Because these gears operate not only at high speeds and loads but also in flexible supporting structures, the production of long-life components is extremely important. Problems arise with respect to quality and the small number of parts that are produced at any given time. Sometimes this number can be 20 or less. Thus, to maintain quality and change to a different production part require continuous setup and adjustment of manufacturing machinery. Derivation from the required tolerances can cause the part to be scrapped at any stage of manufacture.

During the last decade, in response to these production problems, the U.S. Army Aviation Systems Command sponsored projects to improve manufacturing procedures and technology through their Manufacturing Methods and Technology Program (MM\&T). These projects focused on reducing hardware costs by improving productivity and the quality of products that the Army buys.

The two projects discussed herein deal with improvements in the manufacture of spiral bevel gears. The first project involved improving an inspection technique; the second, modifying a manual grinding machine and converting, where appropriate, to computer numerical control. Both projects demonstrated impressive productivity improvements. The inspection technique has been widely adopted, and the improvements to the spiral bevel gear grinding machinery have advanced the state of the art for this and other gear manufacturing tools. 


\section{GEOMETRY OF SPIRAL BEVEL GEARS}

Although the surfaces appear to be involute, they are very different from involute tooth forms. A typical set of gears is shown in figure 1 . Teeth of spiral bevel gears have an axially varying height and thickness that results from the surface generation process used. The basic nomenclature of a spiral bevel gear is shown in figure 2.

The actual geometry of these gear tooth surfaces is a very complex problem to represent mathematically. Spiral bevel gear teeth do not have a closed-form solution to describe their surfaces. In order to determine surface coordinates, the kinematics of the manufacturing process must be modeled; then, a set of simultaneous nonlinear algebraic equations must be solved numerically (1 to 5). ${ }^{*}$ These differences also make the inspection of spiral bevel gears more difficult.

The kinematics of the cutting or grinding process and basic machine-tool settings are shown in figures 3 and 4 , respectively. The milling cutter or grinding wheel is attached to the cradle at a constant location to provide the desired machine settings. The speed of rotation of the cutting surface does not effect the generation of the surface and is set to the best speed for efficient metal removal. The cutter center orbits about the machine center while the gear being generated rotates about its axis. This angular rotation relationship is constant for the milling operation or can be a variable for final grinding. In either operation, the essence of the machine variables is shown in figures 3 and 4 .

Also important to the resultant gear tooth surface geometry are the machine-tool settings shown in figure 4 . Values for the machine settings are usually contained in a summary listing for the particular gear mesh. These machine-tool settings are typically used to begin the manufacturing process. Adjustments to reproduce the

\footnotetext{
*Numbers in parentheses designate references at end of paper.
}

desired gear geometry are more subtle once the basic settings are made.

\section{MANUFACTURE OF AEROSPACE SPIRAL BEVEL GEARS}

The manufacture of spiral bevel gears is a lengthy process. After the gear blanks are machined, there are three main production steps and many intermediate operations. The first step is the gashing operation. Here the spaces are cut between the teeth by using a milling-type cutter. The second step is heat-treating the components to attain the desired surface hardness and case strength. The third step is final grinding to achieve the required gear geometry and tolerances and a low surface roughness. At this point, the gears are ready for service.

The gear is inspected after each manufacturing process and after the final grinding. One of the important inspections, the tooth contact pattern, is conducted by rolling the manufactured gear with a flight-qualified master gear. A master gear has passed a specified and controlled load test for an extended period of time. Thus, the geometry of the pinion and gear are satisfactory for flight whereas gears made in production are attempts to duplicate the masters.

The tooth contact pattern is attained by rolling the production gear with the mating master component. This operation is conducted on a roll tester such as that shown in figure 5 . The driving pinion is run against the driven gear with a light brake load applied. A red lead material is spread on the tooth surfaces so that the points of contact remove the material, leaving locations where contact will take place for the meshing teeth.

The manufacturing process (machine-tool settings) is adjusted for the production components until the desired contact pattern, as well as other quality-control variables, is satisfactory. This continual iteration process makes the final production hardware extremely labor intensive and expensive. 


\section{PRIOR STATE OF THE ART}

Prior to the projects to be described herein and to a certain extent at the present time, the manufacture and inspection of spiral bevel gears are extremely labor intensive and require a high operator skill level. Typically, a trial and error approach at the manufacturing stage was required to reproduce the desired master gear tooth contact patterns. The number of iterations necessary to produce acceptable parts depended on the operator and the number of times a gear had been manufactured in the past.

For the inspection process, current methods utilized for spur and helical gears cannot be used. For parallel-axis gears, traces of the profile deviations are plotted with respect to the expected involute geometry to control profile geometry. For spiral bevel gears, the tooth size and profile shape change as a function of axial position and, thus, this practice would not be practical. Therefore, tooth contact patterns are one of the main criteria used to determine acceptable production gears. A machine that performs this test is shown in figure 5 .

The manufacturing state of the art for facemilled spiral bevel gears involves the use of a completely manual machine tool. This machine tool is capable of making high-quality components but is not able to consistently repeat a prior setup. Highly skilled operators are required to make machine-setting changes to produce the desired surface geometry. Also, once successful production is accomplished, constant minor adjustments are required during production.

Some of the reasons for the lag in machinetool improvements can be traced to the needs of the machine-tool buyers. In the past, before front-wheel-drive passenger vehicles, the auto industry was the main user of these types of tools. $\mathrm{Had}$ this industry continued the use of rear-wheeldrive automobiles, possibly the technology would not have stagnated. Fortunately, because the aerospace gear manufacturing industry was interested in manufacturing technology improvements for this type of gear, projects such as MM\&T were funded to advance gear technology.
IMPROVEMENTS IN SPIRAL BEVEL GEAR INSPECTION

The first MM\&T project to be discussed was one conducted by Sikorsky Aircraft and the Gleason Works (6). The purpose was to develop an automated inspection process by using coordinate measuring machinery, with particular application to spiral bevel gears. A typical coordinate measuring machine is shown in figure 6 .

The first step in this inspection procedure is to digitize the active profile of the master gear component and store this information as the reference surface geometry to be duplicated in production. The orientation of the measuring probe with respect to the components under study is shown in figure 7. A grid of 45 points is used on each side of the gear tooth on the active profile. The grid for a spiral bevel pinion is shown in figure 8 .

Next, the production part is measured and compared to the reference (master) surface. From a comparison of the surfaces, adjustments to the machine settings (see fig. 4) are made, and the trial component is remachined. This process is repeated until the two surfaces agree within a specified tolerance.

Initially, the concept of using a coordinate measurement machine was regarded as another way to scrap good production components. When only the contact pattern test was used, adjustments of the machine tool were made at the discretion of the machine operator, whose skill level was directly related to the quality and quantity of production. In addition, although adjustments were made to start parts production, slight readjustments were typically needed, even during the production cycle. The tooth contact pattern (7) is still used in addition to coordinate measurement; in actuality, coordinate measurement machine adjustments help to control the location and size of the contact pattern attained. Therefore, the machine operator can produce components with fewer iterations and less waste.

A series of production tests was conducted, and the newly developed inspection process was used for in-process and final inspection. The 
average time saved by using this methodology was over $7 \mathrm{hr} / g e a r$. Because the entire profile geometry was being controlled, fewer unusual occurrences resulted during production. Although the main objective of using the coordinate measurement was to improve and control surface geometry, other advantages have been realized. Important information, such as tooth index and spacing errors, has been acquired.

\section{IMPROVEMENTS IN SPIRAL BEVEL GEAR MANUFACTURE}

As mentioned in the section Manufacture of Aerospace Spiral Bevel Gears, quite an extensive setup procedure is required to manufacture spiral bevel gears. Many settings, such as root angle, machine center-to-back, sliding base, etc., on current machines are all made manually. The all-manual, spiral bevel gear grinder shown in figure 9 is capable of making high-quality aerospace gears. However, it has many shortcomings with respect to aerospace gear manufacture because manual adjustments can result in long setup times and improper settings; thus, mistakes in production can easily be made.

The second MM\&T project to be discussed was conducted by Bell Helicopter Textron Inc. and the Gleason Works (8). The purpose of the project was to reduce setup time, improve quality and reduce scrap. The project entailed taking the grinding machine shown in figure 9 and converting, where appropriate, to computer numerical control (CNC). Three of the major improvements will now be described.

The first improvement involved a major change in the generation motion system (or drivetrain) that links the grinding wheel motion to the motion of the gear being ground. This drivetrain had been the source of many production problems, such as tooth spacing errors caused by errors in the drive system itself. Part of the CNC added to this machine was developed to eliminate the vast majority of the drive system. Encoders were employed to maintain the desired relationship between the grinding surface and the workpiece. The conventional (manual) and $\mathrm{CNC}$ versions of the drive system are compared in figure 10.
The second improvement involved altering the grinding wheel dressing system. Grinding is the last operation before the gear is used for power transmission; therefore, surface geometry and finish are related to the dresser to provide the proper cutting surfaces on the grinding wheel. The manual machine used three single-point diamonds to put the desired grinding surfaces on the wheel. The three diamonds traverse the inside, outside, and end of the annular grinding wheel (fig. 11).

One of the problems with the dressing system was that the diamonds wore and affected the grinding wheel surface. Thus, the gear tooth surface geometry and the resultant contact pattern were affected such that part-to-part duplication of the desired gear geometry was difficult and required continual adjustment.

A CNC dresser system was designed and built to eliminate the three-diamond system. The dresser is now comprised of a rotary diamond tool programmed to produce the correct geometry on the grinding surface. With the rotary tool, wear of the diamond dressing surface is greatly reduced; therefore, part-to-part repeatability is greatly enhanced. The improved system is shown in figure 12.

The third improvement involved replacing vernier scales with digital-readout, linear-displacement probes, thus taking the guesswork out of setup variables. The CNC grinding machine resulting from this project is shown in figure 13.

These improvements, and many more not discussed, improved machine productivity and reduced setup time. Thus, the final phase of this MM\&T project was the performance of nine production tests to asses the capabilities of the prototype grinding machine. These tests demonstrated a 65-percent reduction in setup time, which is defined here as the time required to setup the machine to produce a different component, and maintenance of setup time is defined as the time spent during production to make slight machine adjustments. The tests also demonstrated a 34-percent reduction in machining time. 
Many of the manufacturing advances that resulted from this MM\&T program have been implemented in two full CNC spiral bevel gear manufacturing machines now available. One machine is for cutting and another is for grinding. Six axes of computer numerical control (fig. 14) are used to duplicate the motions of the cutting and grinding operation (9 and 10). Now, the machine operator only changes the cutter or grinding wheel and loads the workpiece.

\section{CONCLUSIONS}

Two manufacturing projects funded through the U.S. Army Aviation Systems Command (AVSCOM) were described. The purpose of both projects was to improve specific aspects of the spiral bevel gear manufacturing process. Because of the unique requirements of the aerospace gear manufacturing business, small lot sizes and very tight tolerances, these projects not only lead to improvements in the manufacturing process but also to the removal of some of the magic/black art from making very high-quality aerospace gears. New state-of-the-art inspection techniques were developed and proven to be useful in making machine-tool adjustments before and during production runs. Additionally, these techniques did not result in the scrapping of more production parts as some originally feared. The addition of computer numerical control (CNC) to an all-manual grinding machine also demonstrated that CNC could reduce setup time and improve machinetool performance. The setup time is especially critical for the short production runs typical of the aerospace gear business. Both projects demonstrated that manufacturing improvements could result in substantially reduced inspection and production times, giving U.S. industries improved capabilities.

\section{REFERENCES}

1. L.M. Baxter, "Exact Determination of Tooth Surfaces for Spiral Bevel and Hypoid Gears," AGMA Paper 139.02, Oct. 1966.

2. F. Litvin, "Theory of Gearing," NASA RP-1212, AVSCOM TR-88-C-035, 1989.

3. F. Litvin and H. Lee, "Generation and Tooth Contact Analysis of Spiral Bevel Gears with Predesigned Parabolic Functions of Transmission Errors," NASA CR-4259, AVSCOM TR-89-C-014, 1989.

4. F. Litvin and Y. Zhang, "Local Synthesis and Tooth Contact Analysis of Face-Milled Spiral Bevel Gears," NASA CR-4342, AVSCOM TR-90-C-028, 1991.

5. R.F. Handschuh and L. Litvin, "A Method for Determining Spiral Bevel Gear Tooth Geometry for Finite Element Analysis," NASA TP-3096, AVSCOM TR-91-C-020, 1991.

6. H. Frint, "Automated Inspection and Precision Grinding of Spiral Bevel Gears," NASA CR-4083, AVSCOM TR-87-C-11, 1987.

7. "Understanding Tooth Contact Analysis," The Gleason Works, Rochester, NY, 1981.

8. "H.W. Scott, "Computer Numerical Control Grinding of Spiral Bevel Gears," AVSCOMTR-90-F-6, 1990.

9. T. Krenzer and K. Yunker, "Understanding the Phoenix Universal Bevel and Hypoid Generator," The Gleason Works, Rochester, NY.

10. R. Goldrich, "Theory of 6-Axis CNC Generation of Spiral Bevel and Hypoid Gears," The Gleason Works, Rochester, NY, 1989. 


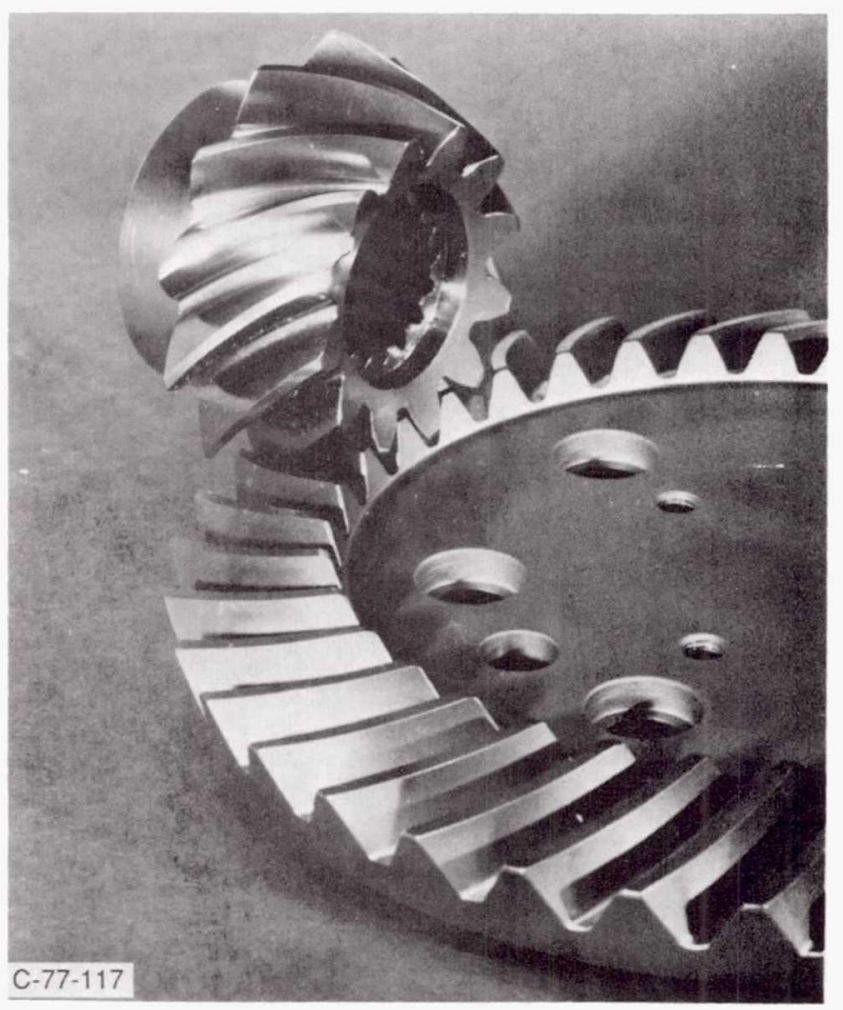

Figure 1.-Typical aerospace spiral bevel gear set.

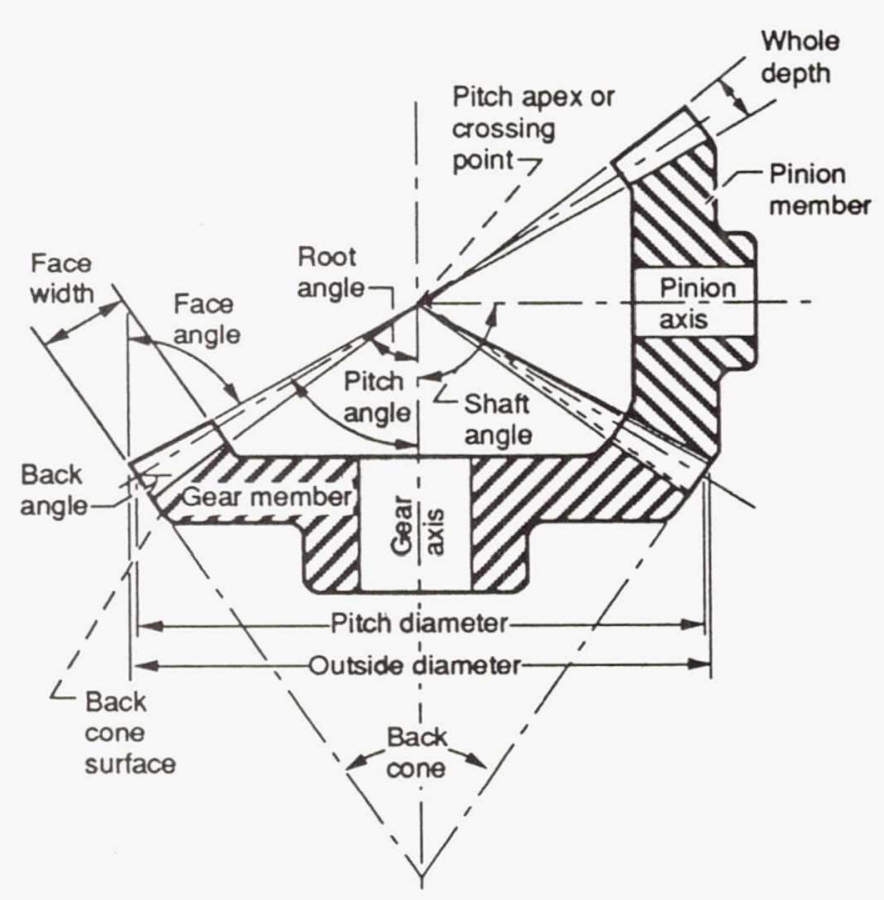

Figure 2.-Bevel gear nomenclature.

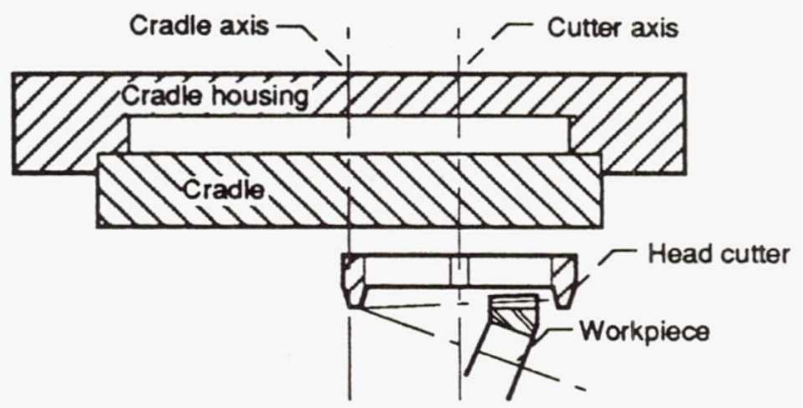

Top view

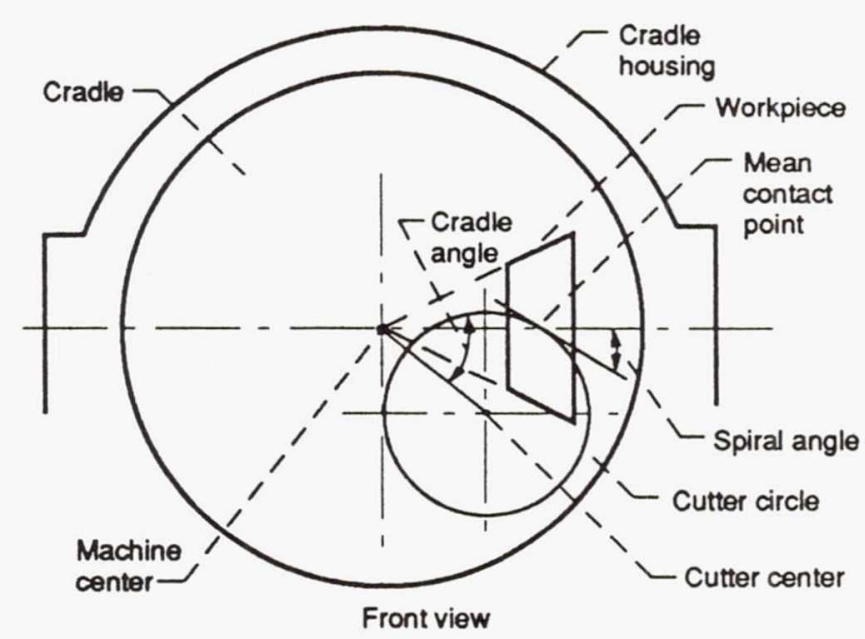

Figure 3.-Basic gear manufacturing setup. 


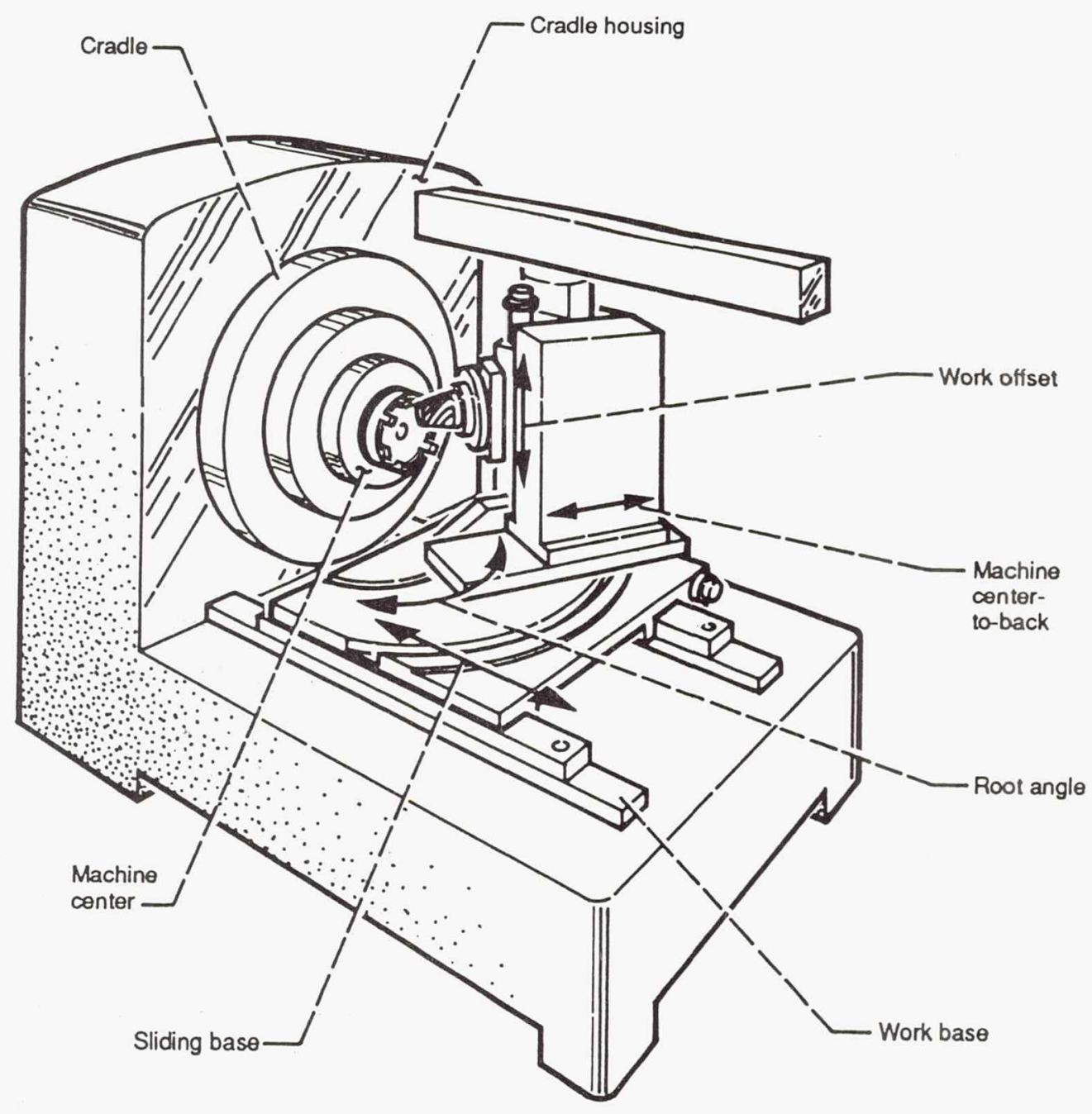

Figure 4.-Basic gear generator and machine settings. 


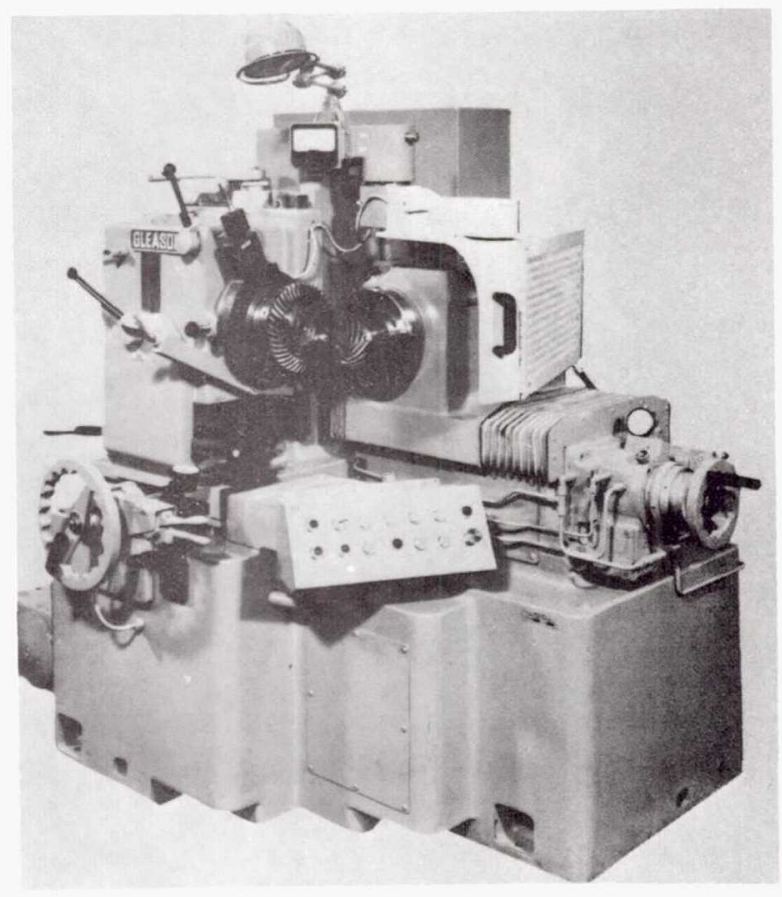

Figure 5.-Contact pattern checking machine.

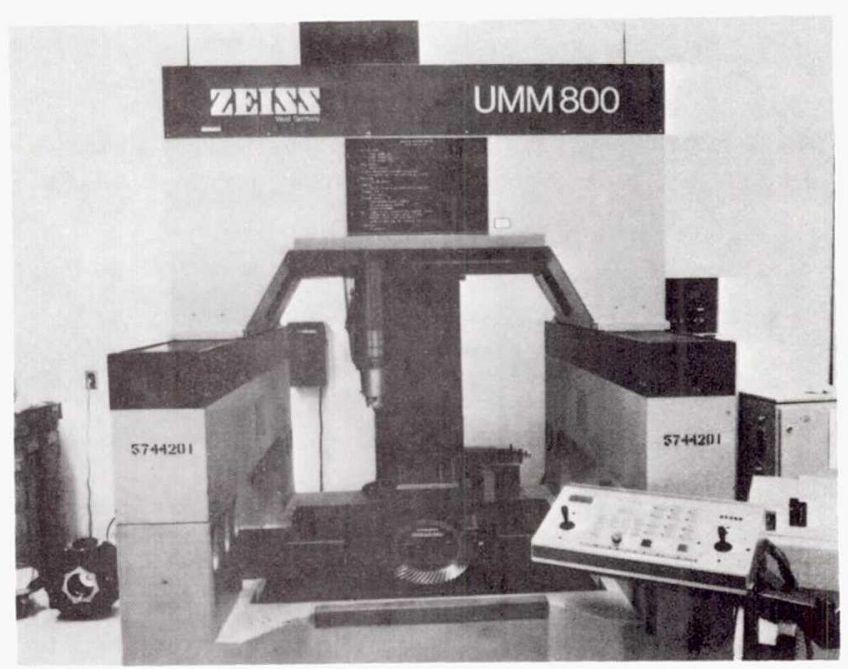

Figure 6.-Coordinate measuring machine.

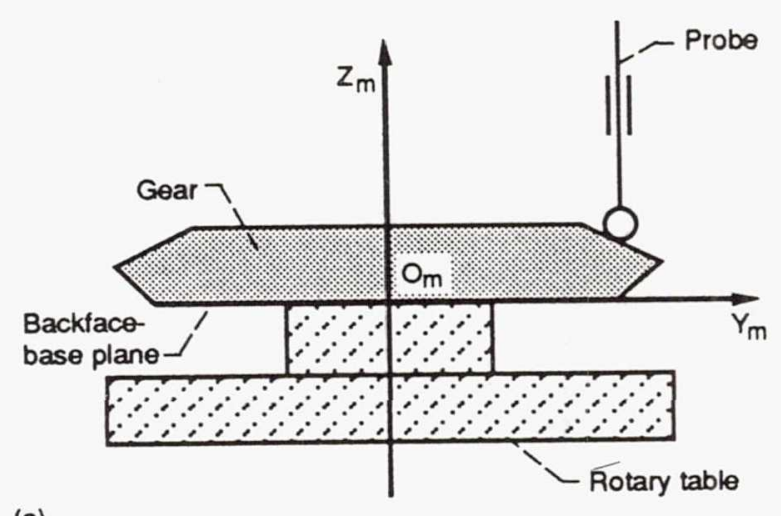

(a)

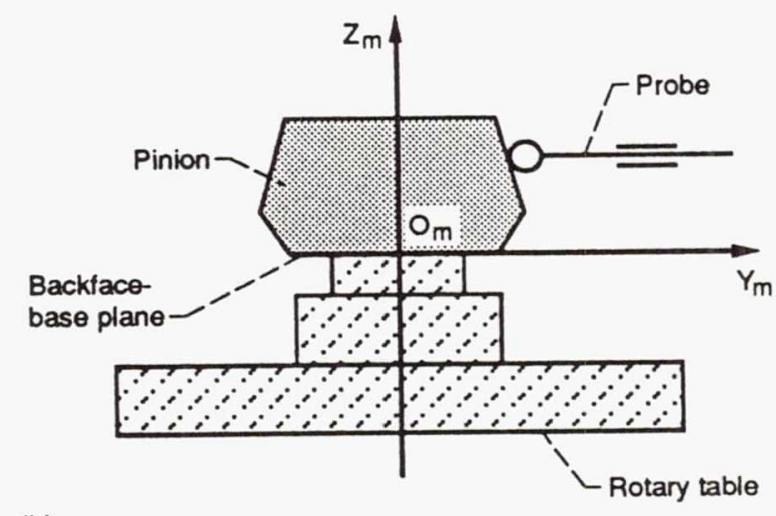

(b)

Figure 7.-Surface measurement probe orientation for (a) gear and (b) pinion. 

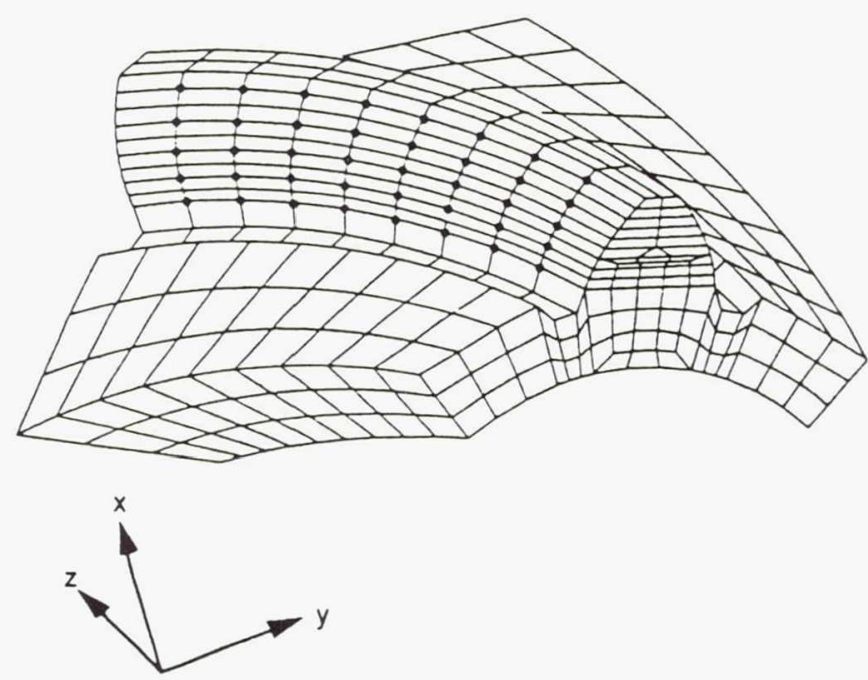

Figure 8.-Measurement grid for a spiral bevel pinion.

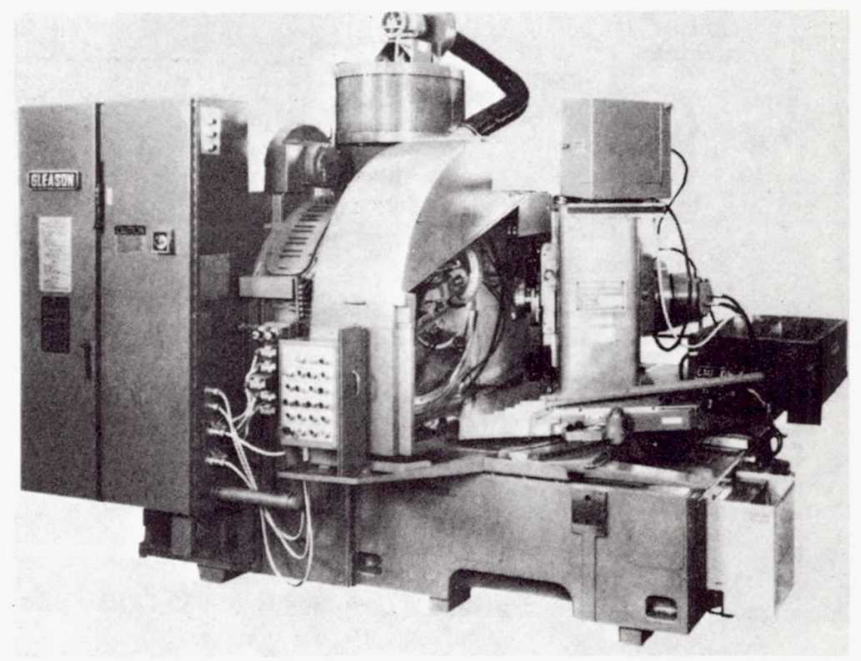

Figure 9.-Manual spiral bevel gear grinder. 


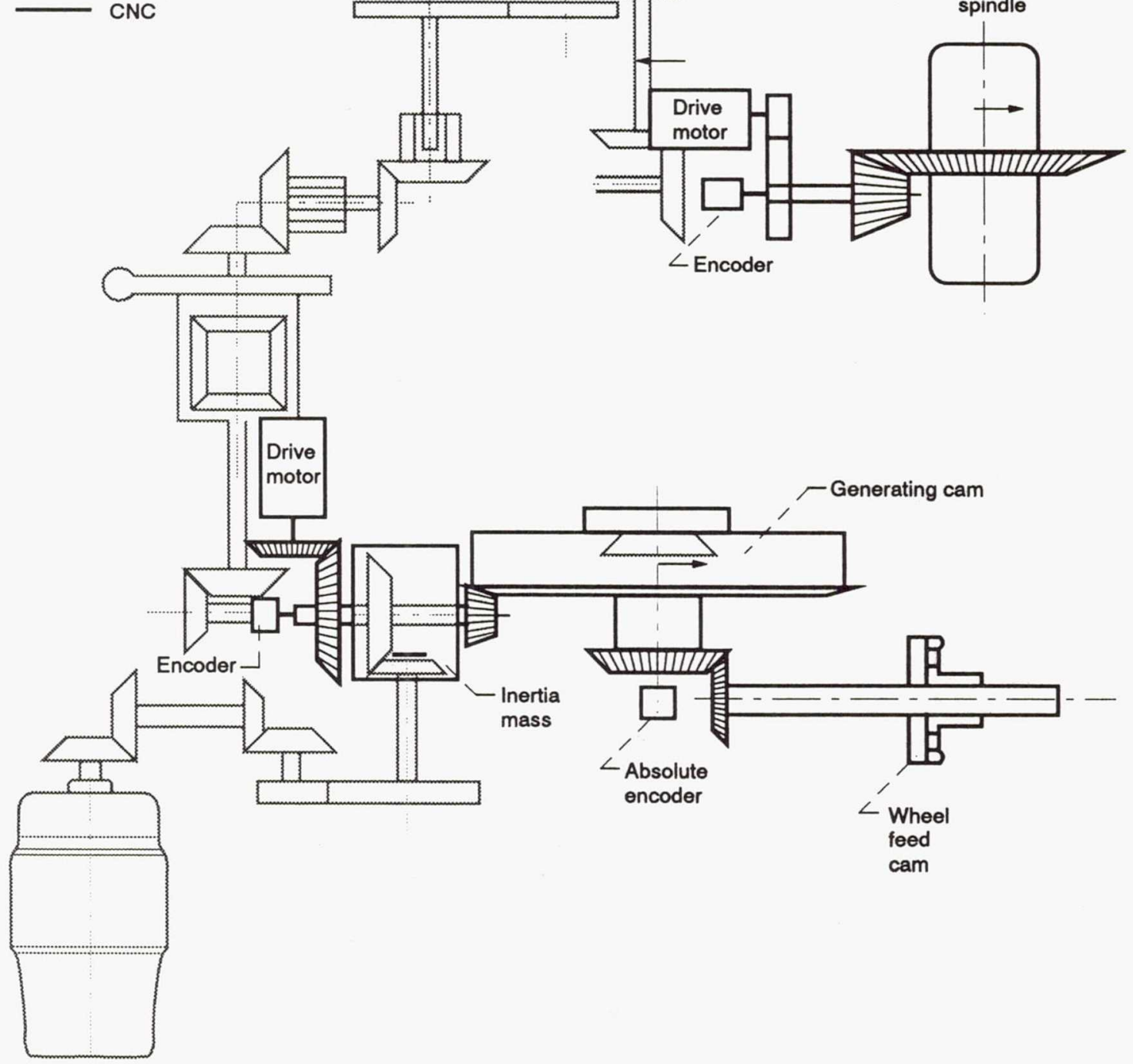

Figure 10.-Generation motion system improvement: drivetrain comparison of $463 \mathrm{CNC}$ and conventional spiral bevel gear grinders. 


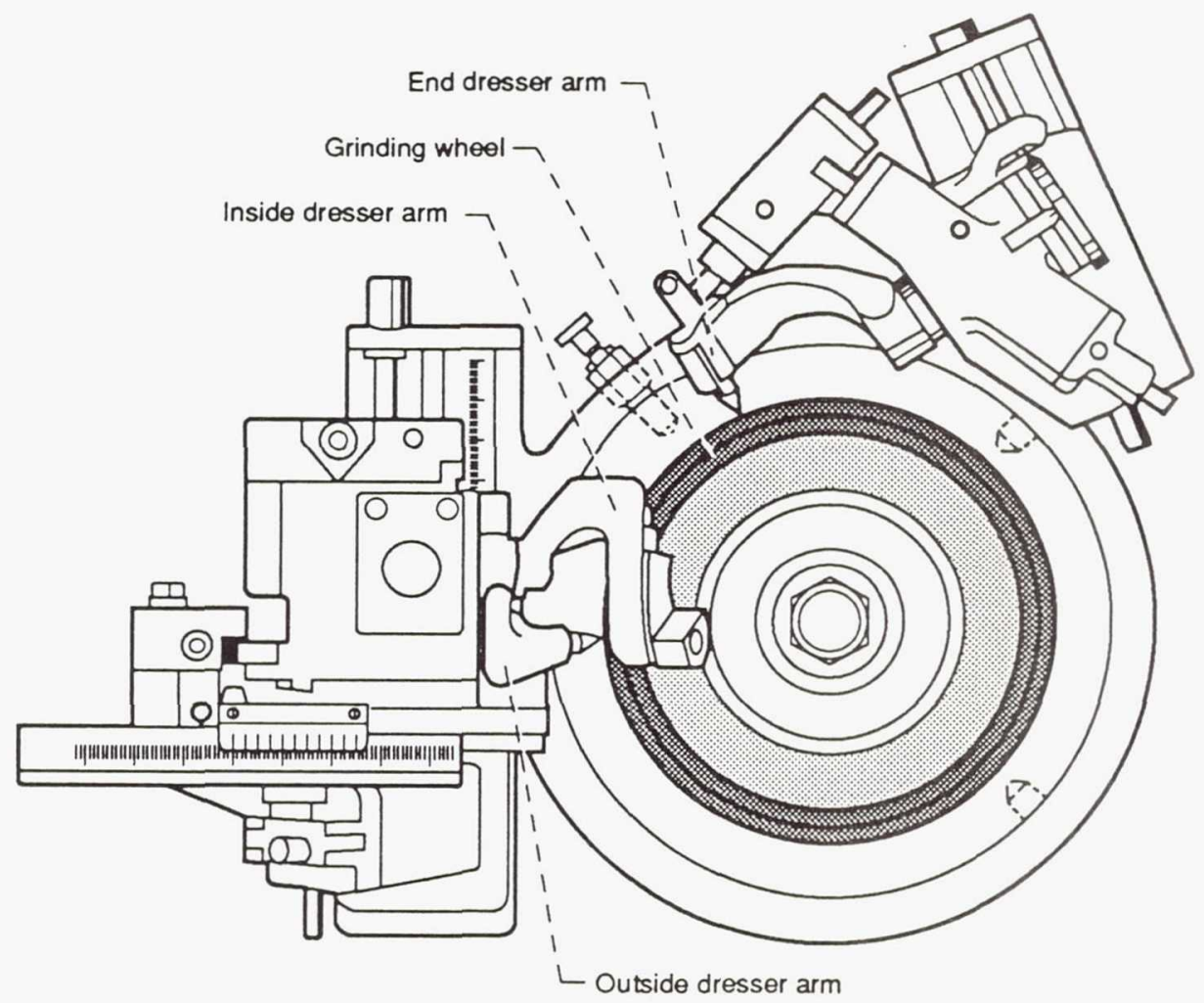

Figure 11.-Manual machine grinding wheel dresser.

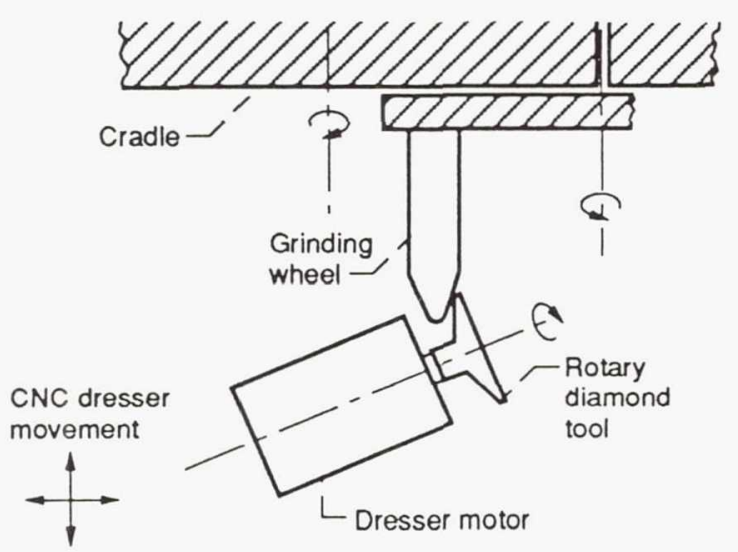

Figure 12.-Improved dresser system with rotary diamond tool.

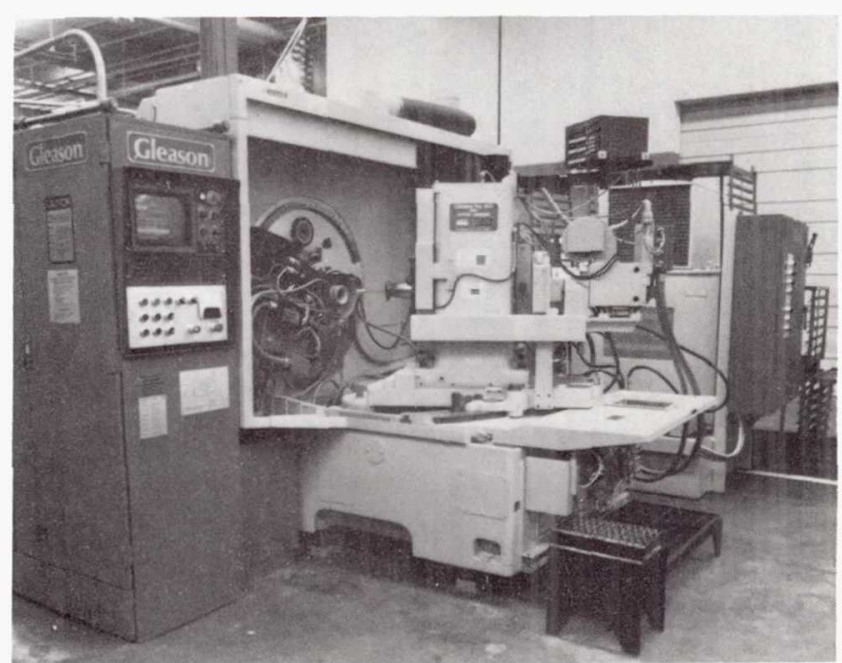

Figure 13.-Computer-numerical-controlled (CNC) spiral bevel gear grinder. 


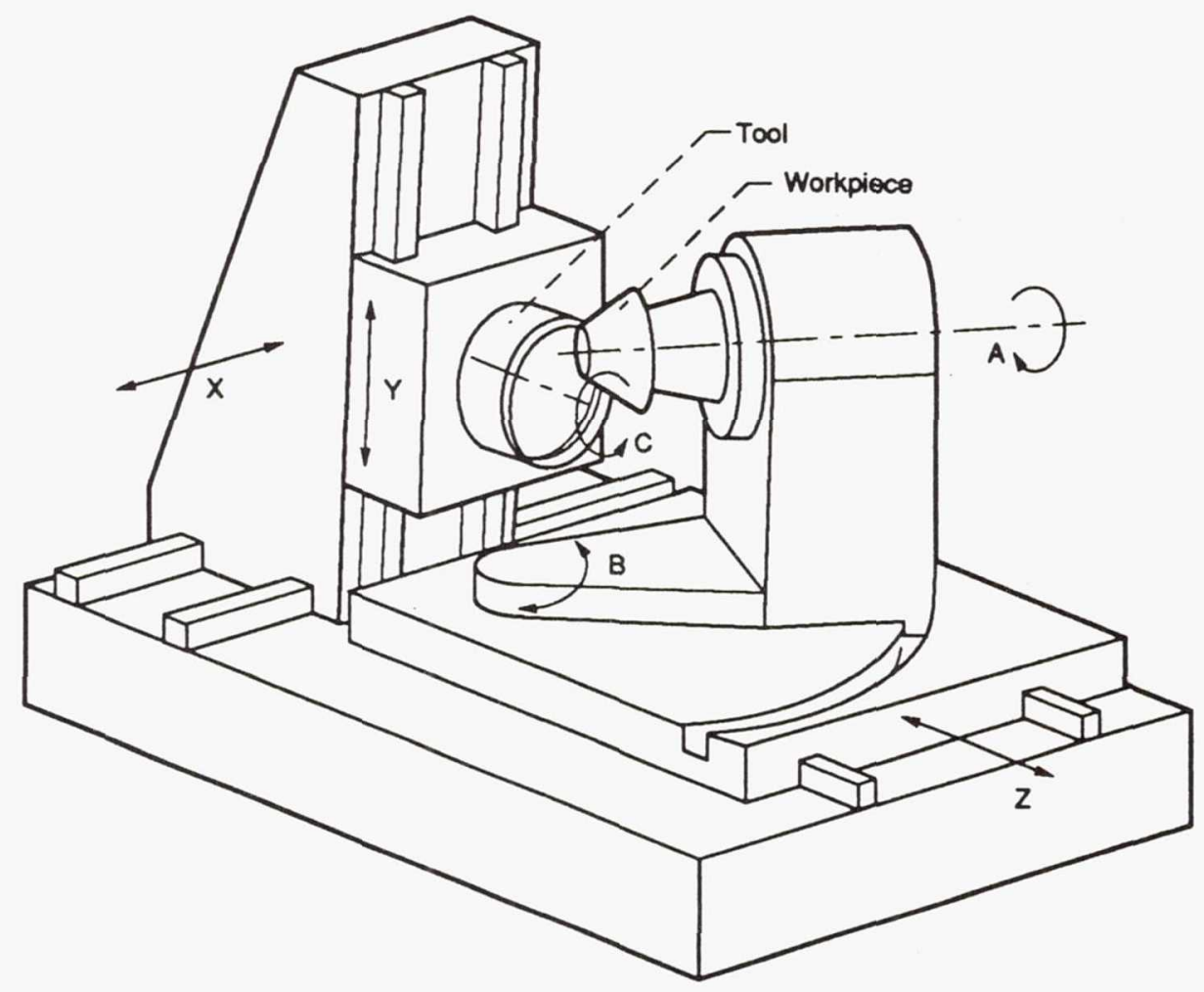

Figure 14.-Full-computer-numerical-controlled (CNC) spiral bevel gear grinder. 


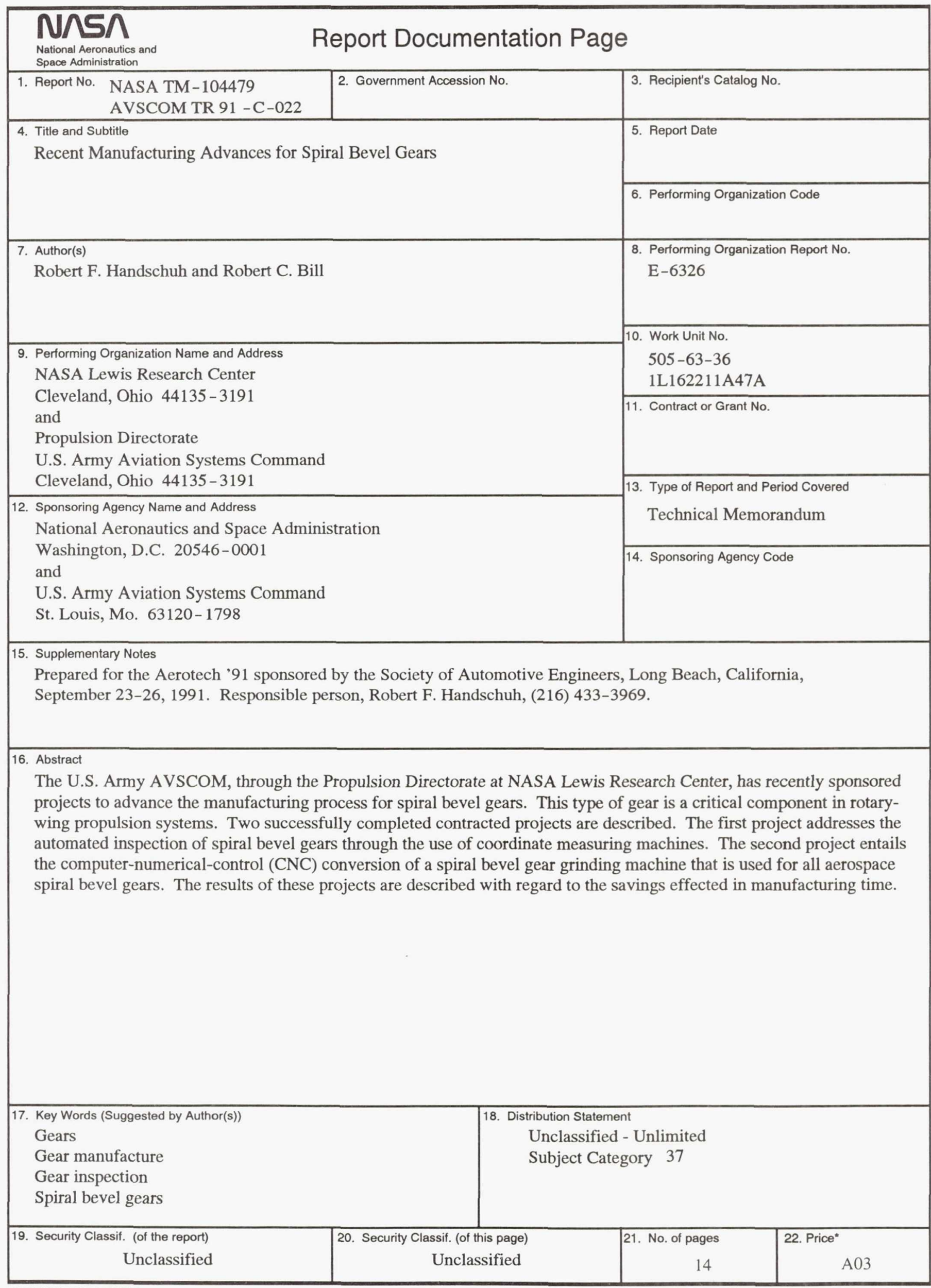

